\title{
Dynamic Assessment in Vygotsky's Sociocultural Theory: Origins and Main Concepts
}

\author{
Samran Daneshfar \\ Department of English Language and Literature, University of Zanjan, Iran \\ Mehdi Moharami \\ Faculty of Education, Monash University, Melbourne, Australia
}

\begin{abstract}
Language assessment is the significant component of foreign language learning/ teaching. An aim of language assessment is to find about how much the process of education improves learners' knowledge of the target language. One alternative to standardized testing, Dynamic Assessment derived from Vygotsky's sociocultural theory offers a new insight into the field of assessment through integrating instruction and assessment. Dynamic assessment is a method of conducting a language testing to investigate and highlight the individual learner's possessed skills and potential development. The present study is going to display an overview of the importance of dynamic assessment in L2 learning, emphasizing the origins and principal concepts involved in the process. The study highlights the derivation of dynamic assessment from Vygotsky's prominent sociocultural theory. Then it brings about an introduction to zone of proximal development the concept of which learner's cognitive development results through the application of dynamic assessment. Later the study discusses dynamic assessment in detail and introduces its differences with the traditional testing formats as well as introducing forms of dynamic assessment.
\end{abstract}

Index Terms - dynamic assessment, sociocultural theory, zone of proximal development

\section{INTRODUCTION}

No EFL program can deny the significance of testing in evaluating the learner's success in learning the target language. The assessment procedure has been currently taken as a sole issue which is applied for different purposes such as prior to learning, for placement reasons or within or after educating like tests in order to get certificates or achievement purposes (Shohamy et.al., 2008). Macrine and Sabbatino (2008) state that new methods to testing like performance, standardized as well as classroom-based ones isolate the test takers over the period of assessment. Poehner (2008) states that one of the difficulties in assessment is that students echo their frustration about the assessment when they are supposed to take systematic methods of testing to confirm their knowledge of the courses or their competency to lead to the following level of education.

Developments in language teaching methodology in the course of time have brought about parallel developments in the field of language assessment. Alderson (2005) emphasizes the importance of assessment in language teaching and learning and argues that while diagnostic tests involve feedback and development recommendations, they are the kind of assessment adequate education purposes. Lantolf and Poehner (2008) believe that although a close connection is a vital requirement for matching education and evaluation, these two procedures are merged well in a new assessment approach originated from L.S. Vygotsky works termed as Dynamic Assessment (DA). The aim of present study is to bring a review of DA in L2 learning as a significant change throughout the process of assessment derived from Vygotsky's (Cultural-historical) Sociocultural Theory (SCT hereafter).

\section{SOCIOCULTURAL THEORY}

According to Murphy (2008), the pioneering founder of DA is the Russian psychologist Lev Vygotsky, and it is based on his unique concept of zone of proximal development (ZPD hereafter) within SCT (Cultural-historical theory). Children are immersed in a social environment where it represents them with all social, cultural and interpersonal experiences. The engagement in cultural connections proves the influential impact of social environment as a key source of development. No human, for instance, born a culturally proficient member; it is necessary to be taught the appropriate cultural practices within the interactions in a society (Rogoff, 2003). Veresov (2017) illustrates that every function in cultural development appears twice: first among people, at the inter-psychological level and later in within the child as an intra-psychological category. The other fundamental concept of the theory according to Veresov is that social relations, social reality is the source of development, and development is the process of how the social becomes an individual.

Poehner (2008) mentions that based on the political and historical conditions, there was a delay of several decades for Vygotsky's outstanding works to be accessible for western psychologists, and has got the attention since the last two decades. The learning in this theory is defined as a social process formed by human intelligence in the culture or society 
the learner lives. The prime concept of Vygotsky's notion highlights the fundamental role of social interaction in the process of cognition development. (Poehner, 2008). According to SCT, teaching is the process of helping learners' developing mental functions. In addition, in SCT, teaching is the process of collaborating with students in the execution of incipient mental functions (Roebuck, 2001).

In DA assessment and instruction are brought together and integration occurs while intervention is inserted within the method of assessment aiming at interpreting the individuals' abilities and leading them to higher levels of functioning (Lidz \& Gindis, 2003). Luria (1979, as cited in Poehner, 2008) states that such integration is based on Vygotsky's developmental perception where progress in the "higher forms of consciousness" like "voluntary control of memory, perception, and attention," happens within a method called "internalization" by which human interactions are representing these functions in early stages and later are converted to higher cognition capabilities which lead to the incorporation of social existence to psychological nature (p. 5).

According to SCT, individuals' responsiveness to support, or mediation, which is sensitive to their present level of ability, discloses cognitive functions that have not yet fully developed. Furthermore, proper mediation allows individuals to surpass their independent performance, and this, in return, stimulates further development (Poehner, 2007). Therefore, DA aims at what individuals are able to do in cooperation with others rather than what they can do alone (Poehner, 2007). The primary concern of DA based on Vygotsky should be the process rather than the final product; furthermore, based on Lantolf and Thorne (2006), the process of investigating the method instead of the outcome would be the sole adequate approach for understanding and signifying the human mental functioning. They continue that this is the distinguishing feature of DA, which the developmental process is the mean of learner's future performance prediction.

\section{ZONE OF PROXIMAL DEVELOPMENT}

Lier (2008) claims that ZPD is the key feature of Vygotsky's cultural-historical theory. Perhaps this notion is the most outstanding and internationally realised scientific heritage of Vygotsky. It is devised to complement the need for a theory about the relationship between specific subject-matter instruction and its consequences for psychological development in child learning (Veresov, 2004). The zone in this concept is mentioned to focus attention on the relationship between instruction and development (Chaiklin, 2003).

To bridge this need, Vygotsky proposes a different approach. He claims that "the child development is not a linear process": in addition, "there are various developmental levels". Based on Vygotsky's notion, in a child's mental functioning coexist tow levels of development. First, "the actual level of development" in which the child can do independently and second, the potential level of development that can be detectable by the tasks the child can accomplish in cooperation the teacher or with a more competent peer. He continues that from these two levels there should be distance between the levels (Veresov, 2004). Brédikyte (2011) argues that Vygotsky adopted ZPD from others, but gave it a new life in his theoretical framework and used it in two contexts - school learning and play.

The commonest meaning of ZPD is the Vygotsky's words which states it as "the distance between the actual developmental level as determined by independent problem-solving and the level of potential development as determined through problem-solving under adult guidance or in collaboration with more capable peers" (Vygotsky, 1978, p. 86). ZPD in cultural-historical theory emphasises "levels of development" in child or learner at beginning levels of learning. In addition, development results from the interaction of the child with a teacher or a more capable peer. Therefore, the fundamental role of education throughout the transition from different levels of development, i.e. the actual to the potential level is unquestionable. Vygotsky's ZPD in applied contexts is defined by the difference between what a child can accomplish unaided and what she can achieve in collaboration with others, both in assessment and in classroom learning situations (Kozulin et.al., 2003). The general conception of ZPD, as Chaiklin (2003) mentions, is an interaction between a more competent person and a less competent one on a task, so that the interaction will result in the development of the less competent one.

Lantolf et.al. (2015) indicate that ZPD does not represent a sole type of the procedure of improvement, rather it is an educational medium applied by the educators in order for a better understanding of the learners' upcoming capabilities. The differences in levels of development or what the individual can do independently or what he or she can do with cooperation are understandable through mediation over time. In other words, it is the concept of mediation in a learning context which defines the transition of the learner from actual levels to the potential ones, where the mediation is given by the teacher or the more "intelligent peer". It can be concluded in this words that in CHT any function in a child's development appears twice: first on the social plane as an inter-psychological function and then within the child as an intra-psychological function. The transition from inter-to intra-psychological functioning takes place in ZPD. (Frawley \& Lantolf, 1985)

\section{DYNAMIC ASSESSMENT}

The concept of mediation (defined in section V) in the zone of proximal development leads educators to consider the notion of pedagogical applications in the classroom contexts. DA is a sub-category of ZPD emerged from Vygotsky's Cultural-historical theory (SCT) which education and evaluation are allied as the elements of that instructional process 
(Lantolf \& Becket, 2009). The term DA originated in a relevant study for the purpose of identifying child's behavioural abnormality which was applied mostly in fields like language impairment as well as learning difficulties up to now. However, other practitioners have started to widen the use of DA practices to second language assessment and pedagogy (e.g., Lantolf \& Poehner 2004 a \& b, Poehner 2005, 2007, 2008, Poehner \& Lantolf 2005).

Bekka (2010) claims that the interaction between the educators and the students in DA creates their ZPD in which the learners' learning potential appears. In other words, to assess a learner's learning potential means to create his or her ZPD through this kind of interaction. DA is concerned with students' learning through making integration between assessment and instruction. The integration here happens when the evaluation process is accompanied by intervention as a way for determining a learner's capabilities and consequently manage the student to higher levels of functioning. In a better explanation, Poehner (2008) argues that the approach highlights to define a child's ZPD and the ability to benefit in cooperation with a more capable person. The higher the amount of benefit attained by mediation (the fundamental concept in DA), the greater ZPD is. This theoretical perspective posits a mediated rather than a direct relationship between humans and the world. As mentioned earlier, based on CHT, just as physical tools mediate our concrete activities that a culture represents, psychological tools mediate mental activities which these tools are internalized interactions resulting from cooperation with others and the application of symbolic artifacts (Poehner, 2008).

Tzuriel (2001) states that DA points to an evaluation of "thinking, perception, learning and problem solving" (concepts highlighted in ZPD) through a teaching procedure aimed at changing cognitive functioning. DA is considered as an overall assessment method which gives the ability to perceive individual's subconscious, emotional and behavioural levels and the interconnections of them. Moreover, the differential aspect of DA to other methods is the focus this method puts on the individual and potential strengths in order to profit from instruction (Smit, 2010).

The procedure of DA has three stages, pre-test, mediated period and post-test. The pretest is followed by the instruction phase, which the child is assisted through instruction in the specified areas which he/she needs help as defined in the pretest. The instruction time or mediated learning experience (derived from Feuerstein's MLE, 1979) provides the learner with related tasks and help him to think about principles and ideas involved in the tests. This era is an adequate opportunity to change the learner's performance within the child's ZPD. At the end, the same pretest is applied as a posttest to mark the final session of the whole assessment process (Mardani \& Tavakoli, 2011).

\section{MEDIATION}

The nature of human underlies interactions with the surrounding in cultural social contexts toward the process of socialization. These interactions require the person engaging in close relation with others and objects to build the theoretical understanding of every communicative process. No doubt the significant means of endowing communication in the society is through language. The mere importance of conceptualizing the language requires the child or the learner to attend in close interaction with the environment and the people.

In a significant differentiation between German, American and Japanese classrooms, Stiengler and Hiebert (1999, cited in Kozulin, et.al 2003, p 1) underscore the importance of a teacher as a mediator between the students and the knowledge in Japanese classroom in a successful educational context. Mediation serves as a keyword in a considerable number of recent studies, some of them inspired by Vygotsky's SCT and some developed independently like Feuerstein (Kozulin 2003). Moreover, Vygotsky in his outstanding concept of SCT argues that the human mental functioning is a mediated process i.e. shaped by cultural artifacts, activities and concepts (Lantolf et. al., 2015) moreover "mediation is the creation and use of artificial auxiliary means of acting — physically, socially, and mentally" (Lantolf, 2011, p.25).

Like ZPD, mediation is essential in DA. Though ZPD is about the individual's potential growth, mediation offers an opportunity for such a growth. There are two distinct notions for the understanding of mediation, mediation through applying tools like computers (Wertsch, 2007), and mediation as the notion of interactions with another human being (Kozulin, 2003). Tools and signs are created by humans and society to achieve a specific need. In particular, psychological tools, also known as semiotic tools, such as language are considered crucial for higher order mental functioning (Kozulin, 2003). Individuals' cognitive development relies on their mastery of these tools. However, these semiotic tools may not work effectively without a human mediator. Therefore, in a learning context, students may not learn by just being exposed to learning materials if the material is not adjusted by a tutor (human mediator).

Kozulin (2003), states that human mediation is the most effective kind of mediation for pedagogical purposes. Vygotsky (1978) defines getting assistance from a more capable person as what the mediation is and therefore mediated activities are explained as the mediums in order to point one's awareness toward the object of consideration applying cooperation. The interactions based on Vygotsky are the prominent aspect of the child's cognition progress, he continues that education and progress or particularly the improvement of higher mental functions happen as the consequences of cooperation in earlier stages between people. Signs and tools materialize the interactions to accomplish a special requirement or to resolve a specific problem. They, however, would involve oral formulations or demands as a sign addressed to the assistance given for solving the task. (Vygotsky, 1978).

Lantolf and Poehner (2004a) highlighted that in DA a specific kind of mediated assistance is provided for the learners; therefore, what makes a kind of assessment dynamic or static (defined in section VI) is not the instrument itself but whether or not mediation is added to the course of the assessment. They explain that multiple-choice, fill-in- 
the-blank, open-ended essay or even oral proficiency tests are in themselves (in nature) neither dynamic nor static instruments. As stated in Poehner and Lantolf (2005) the significant aspect of Feuerstein's 'mediated learning experience' is that environmental stimuli do not directly affect a child but are filtered through some other person, usually a peer above the child's level, who selects and causes the improvement to the child.

Grigorenko (2009) claims that in the concept of ZPD the interactions which occur between the learners and more capable peers predicts the learners' true and closest level of development. The interactions happen as a way to accomplish the students' lack of understanding. The interactors could possibly be both humans as well as other mediums such as textbooks or computers. Shrestha and Coffin (2012) refer to mediation as the intentional cooperation between the teacher or the texts and the students; therefore, mediation could bring a close interaction between the teacher and the learner which consequently leads to the students' improvement under this cooperation.

\section{DynAmiC AND Static AssESSMENT}

DA is regarded as opposed to the traditional methods of testing, or the term that is devised by the specialists in the paradigm of DA as static assessment, in order to distinguish their theoretical perspective from the old types of assessment. While static assessment provides significant information about the student's mental performance, the design of this kind of testing is not directed to present that type of information achieved applying DA approaches. This traditional tests lack aspects such as students' learning potential, mediation procedures, the learning process and special cognitive roles (Tzuriel, 2001). in addition, the major drawback of SA is due to the lack of capability in the way to reveal students' cognitive abilities (Smit, 2010). According to Poehner (2008), assessment and instruction currently exist in a dichotomous relationship. Another significant aspect of DA practice is its integrative facet. The unification of assessment and instruction is grounded in Vygotsky's understandings of development. Sternberg and Grigorenko (2002, as cited in Poehner, 2008) argue that DA offers a theoretically motivated approach to integrating assessment and instruction, something of great importance to learners. With this in mind, DA procedures are crucial to teachers and students and this importance is because of providing a deep insight into the learner capabilities by which are representations of their weak performances and a specific method for support.

Another important aspect in which DA becomes beneficial is that it looks for the future performance of the students through collaboration. Feuerstein et.al., (1979) argue that the traditional concepts of the examiner and examinee roles in the course of assessment should be replaced with the teacher-student relationship and intervention which result in the success of the student. Vygotsky (1978) insisted that the assessment of child's ability through a collaborative activity was a better prediction of future cognitive functioning than a measure of independent performance through traditional tests of intelligence. The collaboration as Vygotsky describes is within the concept of ZPD; therefore, DA should be able to describe the child's ever-changing ability to learn with help or guidance. By collaboration or assisted performance we ask the child to solve the matters beyond his/her mental age with some kind of cooperation and to see how far this cooperation will help the child and as an indicator of the learner's maturing (growing) psychological functions. Brown et.al. (2006) differentiate DA from traditional assessment in which DA emphasizes on children as learners. They focus not only on what the children learn but on how learning occurs. They claim that at the time of the assessment, the assessor intends to observe learning features which could assist in identifying the learner's capabilities and accomplishment to the collaboration.

\section{TYPES OF DYNAMIC ASSESSMENT}

As mentioned above, this is the mediation which makes an assessment dynamic or static; accordingly, the way the examiner mediates is of crucial importance. Mediation can be applied in different styles and Interventionist and Interactionist types are the two main identified methods of DA according to Lantolf and Poehner (2004, a) which usually involve three stages: pretest, mediation phase, and at the end post-test. The distinction between these two procedures varies on the method the mediation is applied throughout the course of the assessment.

\section{A. Interactionist DA}

Interactionist DA as Poehner (2008) states is rooted in Vygotsky's ZPD. The assistance/ mediation in the interactionist procedure of DA derives from the interaction of the learner and the teacher, furthermore sensitive to ZPD of the learner. It aims at the development of the individual or group learner, despite the effort required and with no attention for a predetermined endpoint (Lantolf \& Poehner, 2004, a). No restriction is on the way the mediation, and the mediator applies what he considers most efficient to lead the learners beyond their present level of development. There is no pre-planning for leading questions, hints or help; however, the mediation is derived from the collaborative interaction in the form of dialogues (mediated) in which the teacher responds to the examinee's needs while changing the mediation continually to achieve the proper procedure. (Lantolf \& Poehner, 2011)

In other words, interactionist DA is interpretative and abandons the examinee-examiner relationship in favour of a tutor-student relationship in assessment. In fact, it is in line with Vygotsky's preference for cooperative dialoguing in assessment (Poehner, 2005). Rather than employing a set of predetermined assistance as in interventionist DA, the assistance in interactionist DA develops from a dialogic communication between the student and the teacher as a 
reaction to learners' ZPD. Both sides of the interaction cooperate to achieve the ultimate aim of prosperity (Shrestha \& Coffin, 2012).

\section{B. Interventionist DA}

As opposed to interactionist, in the interventionist method, the tasks and hints are developed to attempt predicting the learners' difficulties which they probably encounter during the course of the assessment. In this approach, mediation is arranged in the form of implicit to explicit types such as hints, prompts, and leading questions. The mediator follows the process precisely and leads the learner from hint to hint (clues) and supports the learner to choose the correct answer which he/she thinks (Lantolf \& Poehner, 2011). It remains closer to certain forms of static assessment and retains the psychometric properties (standardization and scores) of traditional tests. The endpoint for the learner to reach is prespecified and the support is offered and assessed on the basis of the learner's speed to reach the end point (Poehner, 2008).

As stated earlier, there are two kinds of mediation, standardized which all the applicants receive the similar helping hints and non-standardized, which the hints are defined based on the learner's requirements. In the later, it is most likely that the learners do not receive the same assistance regarding the quality and quantity (Lantolf \& Poehner, 2004, b).

It is important to note that within DA the examiner-examinee relationship is based on the idea of teaching and helping, for example, learners are allowed to pose questions and receive immediate feedback. DA, on the other hand, seeks to promote development, therefore, can neither limit nor pre-specify the types of mediation required and must allow the appropriate assistance to emerging in the dialogue between examiner and examinee as they jointly engage in concrete tasks (Lidz \& Gindis, 2003).

\section{Interventionist Sandwich Format}

The sandwich format involves three stages called pretest, mediation (instruction) and posttest. Firstly, the pretest is administered to the applicants; then, the mediation phase is applied as instruction activities (that is pre-planned based on the learner requirements according to the answers to the pretest); and at the end, the same pretest is applied to derive the information as the posttest. As the mediation here occurs between the two pretest and posttest phases, it is termed as sandwiched/ instruction. Mediation in the sandwich structure can be either individualized or group- centred. In the group format, the application of instruction is equal to all the attendees and there is no personalization, therefore, the kind of help to the group style is more implicit in contrast to a more explicitly applied instruction to sole individuals (Sternberg \& Grigorenko, 2002).

Poehner (2008) mentions that Budoff and his colleagues were among the first researchers to experiment with the sandwich format, also called the "pretest-intervention/training-post-test" format. Such an approach to mediation resembles the treatment phase in that the examiner follows a standardized procedure to help the learners in problemsolving strategies. The post-test phase is applied to firstly, compare the learners' performance considering the fact that whether or not experienced help throughout the process, and secondly in order to investigate that in what ways the learners have seen the progression (Grigorenko, 2009).

In a specific study of sandwich form, Kozulin and Garb (2001) applied a DA procedure for developing L2 English reading comprehension ability among academically at-risk high school students. The design included three stages in the pretest stage students were given a standard L2 English test used in pre-academic centres at colleges and universities in Israel. The test used by Kozulin and Garb (2001) contained six sections that stimulated examinees to use cognitive strategies in order to successfully complete reading comprehension tasks. The results obtained from the pretest stage were analyzed in order to develop precise guidelines allowing teachers to mediate each of the six test sections interactively and to ensure that mediation was consistent from one assessor to the other. The guidelines developed were used in the course of the mediation stage. The goal of the mediation process stage was to provide students with appropriate mediation in order to promote their L2 reading development rather than to improve their performance on the pretest stage.

\section{Interventionist Cake Format}

In this format, learners are presented with a series of items, then they face the next question if they give a proper answer to the previous one. Through the process, graded support is presented immediately when difficulties are met, like layers of icing on a cake. The kind of information attained in this part is a good help for the teacher's understanding of the type of suggestion that would be required to assist the educators' needs in accomplishing the tasks (Sternberg, 2005).

According to Sternberg and Grigorenko (2002), a series of pre-decided standard hints are designed to help the learner during the approach till he/she achieves the higher levels in completing the tasks. In an interventionist method, the assistance given to the learners is graded from a range of more implicit to more explicit ones (Lantolf \& Poehner, 2008). A score is given to measure the hints required for the learners in order to accomplish the correct answers and this score could be a representation of the learner's achievement. In other words, this potential development is evaluated through investigating the amount of instruction provided to the learner as a way to master designed tasks and by predicting how the knowledge could be assigned to completely new settings (Grigorenko, 2009). 
Sternberg and Grigorenko (2002) implemented cake format throughout a ten-day DA program. They stated that during the process, the teacher supplied the learners with prompt assistance whenever students made an incorrect whquestion. This DA format helped the teacher to be free for immediate error indication, and the assistance continued till the learner was able to express the question accurately, in this case, the student was faced with the next task. An example of a well-developed interventionist approach to DA that follows a 'cake' format is the Leipzig Learning Test (LLT) developed by Guthke and his colleagues which uses a set of five standardized prompts from implicit to explicit for all learners. The learner's performance is reported in terms of scores (number of prompts and amount of time needed) and profiles (i.e., analysis of error types and responsiveness to prompts). This example shows that interventionist DA retains the psychometric properties (standardization and scores) of traditional tests. In this respect, such assessment may not be sensitive enough to an individual's ZPD. However, the advantage of interventionist DA is its relatively easy application to a large number of learners and thus it can be cost-effective. Furthermore, due to its focus on standardization, interventionist DA has high reliability as it is the case with traditional forms of assessment (Lantolf \& Poehner, 2004a).

\section{CONCLUSION}

Zone of proximal development is the prime concept of Vygotsky's sociocultural theory, where the child's different levels of development are emphasized and are investigated. Scholars utilized this concept and brought it to the area of the classroom to make it applicable to its end of development of the learners. A very significant method to meet the goal of development within ZPD is dynamic assessment based on Vygotsky's model of cognitive development. To put it in other words, DA is grounded in the concept of ZPD and prescribes mediated teacher-learner dialogue during the assessment procedure.

The purpose of DA as discussed in this study is to establish those levels of actual development (what children or learners can do independently) defined in ZPD. In addition, DA attempts to diagnose and assess potential levels of development which are attained by cooperation, or the concept called mediation, between the learner with the teacher or a more intelligent peer. It determines how much learning can take place in ZPD during the process of mediation. DA, suggests that instruction and assessment should be treated two facets of the same as an entity. It implies that when the teachers are determined to understand the students' method of development, the assessment process must not be devoted and centred on the learners' performance through solitary achievement tests. In contrast, the prime attention should be paid to the level of student achievement as a result of collaboration with the teacher or a more capable peer within the period of DA and this type of achievement is representing the learner's potential progress in the future without assistance. The teacher's task is to evaluate learners' exact development following a period of instruction and deciding on the learners' potential development through considering the outcomes. (Lantolf \& Thorne, 2006)

\section{REFERENCES}

[1] Alderson, J.C. (2005). Diagnosing foreign language proficiency: The interface between learning and assessment. London: Continuum.

[2] Bekka, K.G. (2010). Dynamic assessment for learning potential: A shift in the focus and practice of evaluating Japanese oral proficiency. Japanese Journal of Education,10, 53-66.

[3] Bredikytè, M (2011). The zones of proximal development in children's play. Ph.D. dissertation, University of Oulu.

[4] Chaiklin, S. (2003). The zone of proximal development in Vygotsky's analysis of learning and instruction. In A. Kozulin, B. Gindis, V. S. Ageyev, \& S. M. Miller, (Eds.), Vygotsky's educational theory in cultural context (pp. 39-64). New York: Cambridge University Press.

[5] Feuerstein, R., Rand, Y. and Hoffman, M.B. (1979). The dynamic assessment of retarded performers: the learning potential assessment device, 262 Dynamic assessment in the classroom theory, instruments, and techniques. Baltimore, MD: University Park Press.

[6] Frawley, W. \& J. P. Lantolf. (1985). Second language discourse: A Vygotskyan perspective. Applied Linguistics, 6, 19-44.

[7] Grigorenko, E. L. (2009). Dynamic assessment and response to intervention: two sides of one coin. Journal of Learning Disabilities [Online]. 42 (2), 111-132.

[8] Haywood, H. C., \& Lidz, C. S. (2007). Dynamic assessment in practice: Clinical and educational applications. New York: Cambridge University Press.

[9] Kozulin, A. (2003). Psychological tools and mediated learning. In A. Kozulin, B. Gindis, V. S. Ageyev, \& S. M. Miller (Eds.), Vygotsky's educational theory in cultural context (pp. 15-38). New York: Cambridge University Press.

[10] Kozulin, A., \& Garb. E. (2001). Dynamic assessment of EFL text comprehension of at-risk students. Paper presented at the ninth Conference of the European Association for Research on Learning and Instruction, August, 2001. Fribourg, Switzerland.

[11] Kozulin, A., Gindis, B., Ageyev, V.S., \& Miller, S. M. (2003). Vygotsky's educational theory in cultural context. New York: Cambridge University Press.

[12] Lantolf, J. (2011). The sociocultural approach to second language acquisition: Sociocultural theory, second language acquisition, and artificial L2 development. In D. Atkinson (ed.), Alternative approaches to second language acquisition. London: Routledge, 24-47.

[13] Lantolf, J. P., \& Poehner, M. E. (2004, a). Dynamic assessment of L2 development: Bringing the past into the future. Journal of Applied Linguistics, 1 (1), 49-72. 
[14] Lantolf, J. P., \& Poehner, M. E. (2004, b). Dynamic assessment in the language classroom. Retrieved from CALPER website: http://calper.la.psu.edu/publications.php. (accessed 2014/2/1).

[15] Lantolf, J. P., \& Poehner, M. E. (2008). Language testing and assessment. In E. Shohamy, \& N. H. Hornberger, (Eds.), Encyclopedia of language and education (pp. 273-284). Berlin: Springer.

[16] Lantolf, J. P., \& Poehner, M. E. (2011). Dynamic assessment in the classroom: Vygotskian praxis for second language development. Language Teaching Research, 15 (1), 11-33

[17] Lantolf, J. P., \& Thorne, S. L. (2006). Sociocultural theory and the genesis of second language development. Oxford: Oxford University Press.

[18] Lantolf, J., \& Beckett, T. (2009). Sociocultural theory and second language acquisition. Language Teaching, 42(4), $459-475$.

[19] Lantolf, J., Thorne, S. L., \& Poehner, M. (2015). Sociocultural Theory and Second Language Development. In B. van Patten \& J. Williams (Eds.), Theories in Second Language Acquisition (pp. 207-226). New York: Routledge.

[20] Lidz, C.S., \& B. Gindis. (2003). Dynamic assessment of the evolving cognitive functions in children. In A. Kozulin, B. Gindis, V. S. Ageyev, \& S. M. Miller (Eds.), Vygotsky's educational theory in cultural context (pp. 99-116). New York: Cambridge University Press.

[21] Lier, L.V. (2008). The ecology of language learning and sociocultural theory. In A. Creese, P Martin, \& N. H. Hornberger (Eds.), Encyclopedia of language and education, (pp. 53-65). Berlin: Springer.

[22] Luria, A.R. (1979). The making of mind: A personal account of soviet psychology. Cambridge MA: Harvard University Press.

[23] Macrine, S. L., \& Sabbatino, E. D. (2008). Dynamic assessment and remediation approach: Using the DARA approach to assist struggling readers. Reading \& Writing Quarterly, 24(1), 52-76.

[24] Mardani, M., \& Tavakoli, M. (2011). Beyond Reading Comprehension: The Effect of Adding a Dynamic Assessment Component on EFL Reading Comprehension. Journal of Language Teaching \& Research, 2(3).

[25] Minson, V., Hammer, M., \& Veresov, N. N. (2016). Rethinking assessments: creating a new tool using the zone of proximal development within a cultural-historical framework. Cultural-Historical Psychology, 12(3), 331-345.

[26] Moore-Brown, B., Huerta, M., Hernandez, Y.U., \& Pena, E.D. (2006). Using dynamic assessment to evaluate children with suspected learning disabilities. Intervention in School and Clinic. 41(4), 209-217.

[27] Murphy, R. (2008). Dynamic assessment precursors: Soviet ideology and Vygotsky. The Irish Journal of Psychology, 29(3-4), 193-233.

[28] Poehner, M. E, \& Lantolf, J. P. (2005). Dynamic assessment in the language classroom. Language Teaching Research 9 (3), 233-265.

[29] Poehner, M. E. (2005). Dynamic assessment of oral proficiency among advanced L2 learners of French. Ph.D. dissertation, Pennsylvania State University.

[30] Poehner, M. E. (2007). Beyond the test: 12 dynamic assessment and the transcendence of mediated learning. The Modern Language Journal, 91(3)323-340.

[31] Poehner, M. E. (2008). Dynamic assessment: A Vygotskian approach to understanding and promoting 12 development. Berlin: Springer.

[32] Roebuck, R.F. (2001). Teaching composition in the college level foreign language class: Insights and activities from sociocultural theory. Foreign Language Annals, 34(3), 206-215.

[33] Rogoff, B. (2003). The cultural nature of human development. New York: Oxford University Press.

[34] Shohamy, E., Inbar-Lourie, O., \& Poehner, M. (2008) Investigating Assessment Perceptions and Practices in the Advanced Foreign Language Classroom (Report No 1108). University Park, PA: Center for Advanced Language Proficiency Education and Research (CALPER).

[35] Shrestha, P., \& Coffin, C. (2012). Dynamic assessment, tutor mediation and academic writing development. Assessing writing, 17(1), 55-70.

[36] Smit, M. (2010). Educational psychologists' view of the relevance of dynamic assessment for their practice. Ph.D. dissertation, University of Stellenbosch.

[37] Sternberg, R.J. \& Grigorenko, E.L. (2002). Dynamic testing: The nature and measurement of learning potential. Cambridge: Cambridge University Press.

[38] Sternberg, R.J. (2005). Intelligence, competence, and expertise. In A.J. Elliott, and C.S. Dweck, (Eds.), Handbook of competence and motivation. New York: The Guilford Press.

[39] Stiengler, J., \& Hiebert, J. (1999). The teaching gap. New York: Free Press.

[40] Thouësny, S. (2011). Modeling second language learners' interlanguage and its variability. Ph.D. dissertation, Dublin City University.

[41] Tzuriel, D. (2001). Dynamic assessment of young children. New York: Plenum Publishers.

[42] Veresov, N. (2004). Zone of proximal development (ZPD): the hidden dimension? Anna Lena Ostern \& Ria Heila Ylikallio (eds.). Language as culture tensions in time and space. Vol. 1, p. 13-30.

[43] Veresov, N. N. (2017). ZBR and ZPD: Is there a difference? Cultural-Historical Psychology, 13(1), 23-36.

[44] Vygotsky, L. (1978). Mind in society. Cambridge, MA: Harvard University Press.

[45] Wertsch, J. V. (2007). Mediation. In H. Daniels, M. Cole \& J. V. Wertsch (Eds.), The Cambridge Companion to Vygotsky (pp. 178-92). Cambridge: CUP. 


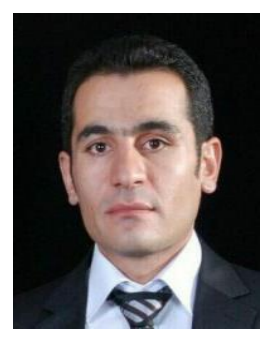

Samran Daneshfar was born in Piran Shahr, Iran. He received a B.A. in English Language and Literature from Urmia University-Iran (2009) and he is an MA graduate in English Language Teaching (TEFL) from the University of Zanjan-Iran (2014). He is currently an experienced EFL teacher in Ministry of Education in Piran Shahr. He is teaching at junior secondary school. His areas of interest are applied linguistics, Teaching English to Speakers of Other Languages (TESOL), the Sociocultural Theory and Dynamic Assessment in second language. E-mail: s.daneshfar82@gmail.com

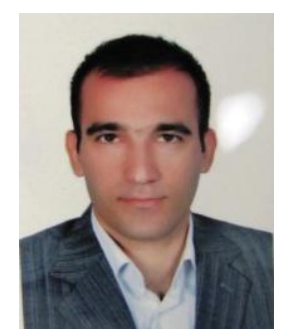

Mehdi Moharami is a Ph.D. candidate in the faculty of education - Monash University. He received his Master Degree in teaching English as a foreign language (TEFL) from Zanjan University - Iran. He is doing his studies on the influence of English language teaching on cultural change of Iranian language learners and society. His areas of interest are Language Education, Identity Formation, Culture, and Sociology. E-mail: Mehdi.moharami@monash.edu 